\title{
Fracturas e pseudartroses da apofise do unciforme - 10 casos
}

\author{
J. C. Botelheiro, S. Silverio ${ }^{(1)}$, C. Irisarri ${ }^{(2)}$ \\ ${ }^{(1)}$ MEDIS ACIDENTES, LISBOA \\ ${ }^{(2)}$ LA FRATERNIDAD, VIGO
}

Correspondencia:

Dr. J. C. Botelheiro, Hospital de Sant'Ana

Rua de Benguela, 2779-501 Parede, PORTUGAL

\begin{abstract}
Se presentan 10 casos de fractura y pseudartrosis de la apofisis del hueso ganchoso. 9 han sido operados - excisión de la apofisis por vía palmar. 3, diagnosticados precozmente, habían sido inmovilizados pero no se obtuvo consolidación en ninguno de ellos, pero uno se quedo sin dolor. 7 fueron diagnosticados como pseudartrosis dolorosas o fracturas con varias semanas de evolución. De los 9 pacientes operados 8 quedaron asintomáticos. Así, la excisión quirúrgica nos parece el tratamiento de elección para las pseudartrosis y fracturas dolorosas de la apofisis del hueso ganchoso.
\end{abstract}

Palabras clave: Hueso ganchoso, fracturas, pseudartrosis.
Fractures and pseudarthroses of the hook of the hamate - 10 cases. We describe 10 cases of fractures and pseudarthroses of the hook of the hamate. 3 fresh fractures were immobilised but none went to union, although one was painless. The other two and 7 late diagnosed fractures or painfull nonunions were operated - excision of the hook of the hamate- 6 of them becoming painless. This led us to conclude that surgical excision is the correct treatment for painful fractures and nonunions of the hook of the hamate.

Key words: Hamate, hook, fractures, pseudarthrosis.

\section{INTRODUÇÃO}

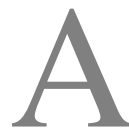

s fracturas da apófise do unciforme são raras, a avaliar pelos números das séries publicadas, sendo a maior parte delas diagnosticadas tardiamente como pseudartroses dolorosas (Foucher et al., 1985; Le Viet, Lantieri e Bouvet, 1993).

As etiologias mais frequentes parecem ser as quedas sobre a mão e os traumatismos desportivos indirectos, da mão dominante nos jogadores de ténis e da mão dominante nos de golfe (Le Viet, Lantieri e Bouvet, 1993; Moura e Botelheiro, 1994).
O diagnóstico pode suspeitar-se clinicamente pela dor referida a emineência hipotenar que e confirmado pela palpação muito dolorosa num ponto $1 \mathrm{~cm}$ para dentro e $2 \mathrm{~cm}$ distal ao pisiforme, embora alguns doentes refiram a dor mais dorsal.

O diagnostico definitivo é geralmente feito hoje em dia pela tomografia axial computorizada, embora existam técnicas de radiografía clássica especificas para a apófise do unciforme a incidência do canal cárpico que obriga a uma dorsiflexão forçada do punho difícil de conseguir num punho doloroso e sobretudo a incidência descrita por Papilion (Schernberg, 


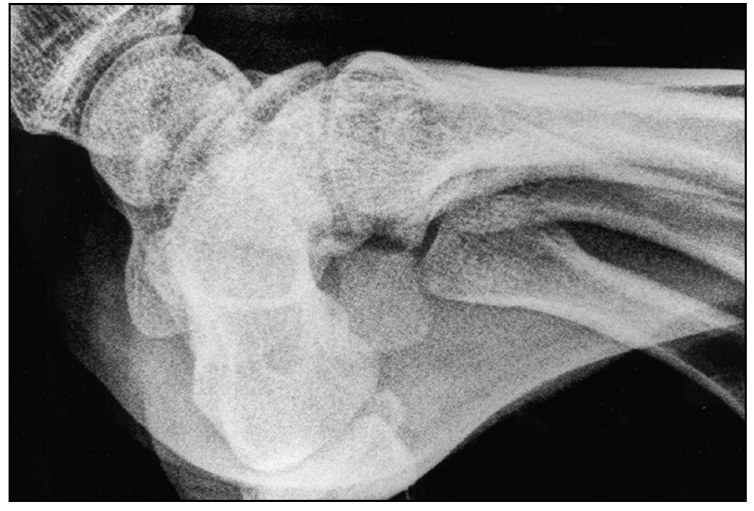

Figura 1. Fractura da apófise do unciforme diagnosticada pela incidência de Papilion.

1992). Esta é um perfil supinado a 30 o da mão, com inclinação radial desta, penetrando o feixe de RX pela primeira comissura com abdução do polegar (Figura 1).

O diagnostico diferencial deve ser feito com a bipartição congénita do unciforme - o «os hamuli proprium». Se a lesão for bilateral será em principio um unciforme bipartido. Se for unilateral, deverá suspeitar-se duma pseudartrose congénita se não houver traumatismo desencadeante das queixas e se os bordos da pseudartrose forem de osso cortical, sobretudo se a Ressonância Magnética ai demonstrar superfícies cartilagíneas (Mantovani, Trevisan en Martelli, 2002).

Alguns autores citam diversas complicações destas pseudartroses, como tendinites ou mesmo roturas dos tendões flexores dos dedos mais cubitais e sinais de compressão do nervo cubital au até do mediano (Le Viet, Lantieri e Bouvet, 1993).

Para as fracturas foi aconselhado o tratamento conservador por alguns autores gesso antebráquio-palmar englobando os $4 \mathrm{o}$ e 50 dedos com as MF em flexão, para relaxar a musculatura hipoténar que se insere na apófise do unciforme, durante 6 a 8 semans (Foucher et al., 1985).

Para as pseudartroses dolorosas a maioria dos autores aconselha a excisão cirúrgica de apófise, incluindo a sua base para evitar atrito sobre os tendões flexores dos dedos. Apenas Kirk Watson aconselha a osteossíntese com fios de Kirchner e enxerto ósseo, com o argumento de que a falta da apófise unciforme alongaria o curso dos tendões flexores dos 4 o e 5 o dedos

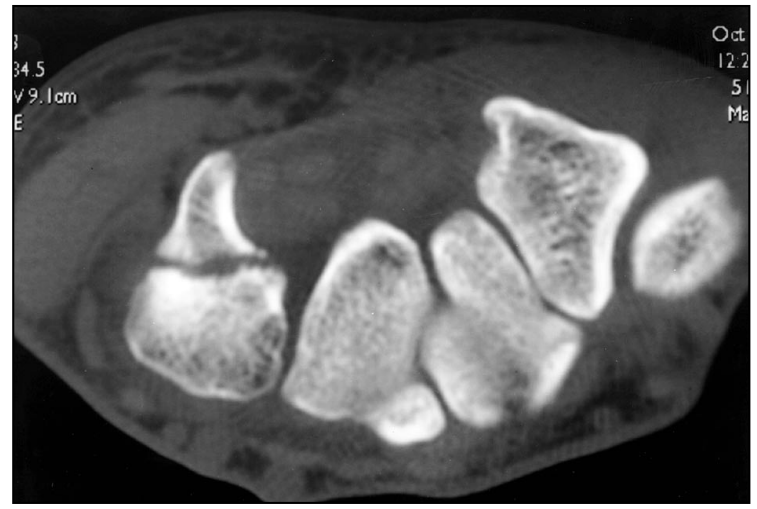

Figura 2. TAC de uma pseudartrose da apófise do unciforme.

com a consequente diminuição da forca de preensão (Watson, 1989), o que a prática da excisão não confirma.

Quanto às vias de acceso para a excisão estão descritas 3. A maioria dos autores (Foucher et al., 1985) aconselha uma via palmar directa iniciando-se no canal de Guyon e seguindo o trajecto do nervo cubital distalmente - este passa entre o pisiforme e a apófise do unciforme, $2 \mathrm{~cm}$ mais distal e $1 \mathrm{~cm}$ mais radial, embora num plano um pouco mais superficial que esta. Le Viet (1993) aconselha uma exposição larga do canal cárpico, do qual a apófise do unciforme é o limite cubital, o que parece indicado quando haja lesões dos tendões flexores a reparar. Já Mizuseki (1986) aconselha uma via lateral cubital, sob a massa muscular hipoténar, ruginando o carpo até à base da apófise, o que segundo esses autores torna difícil o acceso à ponta da apófise. Alguns autores realçam o facto de a pseudartrose não ser por vecez aparente durante a cirurgia (Mizuseki, 1986).

\section{MATERIAL E MÉTODOS}

No final deste artigo encontra-se um resumo dos 10 casos da nossa série, 5 de Lisboa (JCB, 1 a 5) e 5 de Espanha (CE, A a E).

As fracturas foram causadas por uma queda sobre a mão em 8 casos, por um traumatimo indirecto com a pega de um taco de golfe num jogador profissional e mecanismo desconhecido noutro caso, eventualmente uma pseudartrose congénita. Neste último caso a pseudartrose da apófise do unciforme foi diagnosticada num 
TAC feito a uma doente que tinha um quisto sinovial intraósseo do semi-lunar.

Em nenhum dos casos desta série existiam sinais de compressão nervosa ou de tendinite dos flexores dos dedos.

O diagnóstico de todos os casos foi confirmado por tomografia axial computorizada, embora em 2 tivesse sido feito antes por radiografia convencional com incidência de Papillion.

As fracturas e pseudartroses eram da base da apófise em 7 doentes e da ponta em 2, sendo a localização não referida num outro. De notar que num caso coexistia uma fractura do corpo do unciforme.

Em 3 casos, diagnosticados precocemente, foi feita uma tentativa de tratamento conservador, com gesso antebráquio-palmar, durante 5 a 10 semanas. $\mathrm{O}$ caso imobilizado 10 semanas tinha uma fractura sem desvio do escafóide, pela qual foi imobilizado - o escafóide consolidou mas manteve dores na região hipoténar e o TAC mostrou então una fractura não consolidada da apófise do unciforme! Também os outros não consolidaram, embora um tenha ficado indolor — um jogador de «volley» em que a fractura do corpo do unciforme consolidou, embora não a da apófise.

Por este motivo, optamos pelo tratamento cirúrgico - excisão da apófise e sua base por via palmar - em 2 outros caso diagnosticados precocemente e nos restantes, diagnosticados já como pseudartroses - 9 no total. A imobilização pósoperatória foi curta, apenas até à extracção dos pontos, começando-se então a mobilizacao activa livremente. Nao registamos quaisquer complicações pósoperatórias nos nossos casos.

Dos 5 casos operados em Lisboa, a apófise do unciforme apresentava intraoperatoriamente mobilidade em apenas 2 casos.

Um bom resultado final, com mobilidade completa e indolora do punho, foi rapidamente obtido em 8 casos operados, dos quais 6 eram acidentes laborais, tendo o jogador profissional de golfe retomado o seu nível competitivo anterior. Apenas a doente, também considerada acidente laboral, operada a um quisto sinovial intra-ósseo do semi-lunar concomitante, manteve dores.

\section{CONCLUSÕES}

Como conclusões desta nossa experiência podemos apresentar as seguintes.

As fracturas e pseudartroses da apófise do unciforme devem suspeitar-se nos casos de dor pos-traumática da regiao hipoténar, especificamente à palpação dum ponto distal e cubital ao pisiforme.

O seu diagnóstico pode ser feito pela incidência radiológica de Papillion e seguramente pela TAC.

A imobilização não parece levar à consolidação destas fracturas.

A excisão cirúrgica da apófise por via palmar, embora delicada, garante um bom resultado funcional, pelo que parece o tratamento aconselhável nas pseudartroses e fracturas dolorosas da apófise do unciforme.

\section{BIBLIOGRAFÍA}

Foucher, G.; Schuind, F.; Merle, M.; Brunelli, F.: Fractures of the hook of the hamate. J. Hand Surg, 10 B, 205-210, 1985.

Le Viet, D.; Lantieri, L.; Bouvet, R.: La pseudarthrose de l'apophyse unciforme de l'os crochu. Rev Chir Orthop, 79, 292-298, 1993.

Mantovani, A.; Trevisan, M.; Martelli, S.: La psedartrosi conge- nita dell'apofisi unciforme deIl'osso uncinato - descrizione di due casi associati a patologia. Riv Chir Mano, 39(2), 167174, 2002.

Moura, F.; Botelheiro, J. C.: Pseudartrose da apofise do unciforme - caso clinico. Rev Port Ortop Traum, 2:2, 165-166, 1994. Mizuseki, T.; Ikuta, Y.; Murakami, T.; Watari, S.: Lateal approach to the hook of the hamate for its fracture. J. Hand Surg, 11 B, 109-111, 1986.

Schernberg, F.: Le poignet, anatomie radiologique et chirurgie. Masson, Paris, 1992.

Watson, H. K.; Rogers, W. D.: Nonunion of the hook of the hamata - an argument for bone grafting the nonunion. J. Hand Surg, 14 A, 486-490, 1989. 


\section{RESUMO DOS CASOS}

Caso 1, 1993.

CA, profissional de golfe, masc.

Dor na eminência hipoténar de mão esqueda há

1 ano, desde violento «groundshot».

TAC - pseudartrose.

Cirurgia - excisão de apófise móvel.

Retomou golfe profissional.

Caso 2, JFSR, masc., 25.

4-7-2000 Fractura do escafóide esq. imobilizada ate 20-9, consolidada.

9-2-2001 Dor na eminência hipoténar.

23-2-2001 TAC - pseudartrose da apófise do unciforme.

13-3-2001 Excisão de apófise aparentemente consolidada.

13-5-2001 Alta sem dores.

Caso 3, AFA, 40.

14-7-2001 Queda, dor na eminência hipoténar.

23-7 RX (Papillion) - fractura da apófise do unciforme.

26-7 TAC confirma. Imob. gessada até 14-9.

12-10 Dores. TAC - consolidação duvidosa.

30-10 Operado - excisão da apófise aparentemente consolidada.

21-1-2002 Alta sem dores.

Caso 4, PNNE, masc, 28.

23-9-2001 Queda de moto.

9-11 TAC - fractura da base da apófise do unciforme.

20-11 Operado - excisão de apófise móvel.

4-1-2002 Alta sem dores.
Caso 5, PJBB, 40.

5-12-2001 Queda sobre a mão dta.

16-1-2002 Dores sugestivas, RX duvidoso, TAC típico. Continua a trabalhar, mantém dores.

15-3-2002 Operado - excisão de apófise aparentemente consolidada.

6-2002 Alta sem dores.

Caso A, jogador de volley, 24.

Queda sobre a mão.

TAC - fractura do corpo e da apófise do unciforme imbilizada 5 semanas.

Pseudartrose da apófise indolor.

Caso B, trabalhador manual.

Queda sobre a mão, dores persistentes.

TAC - pseudartrose da ponta da apófise.

Operado. Alta aos 2 meses.

Caso C, 40 anos, empresário.

Pseudartrose da ponta da apófise do unciforme dolorosa na actividade desportiva.

Operado, retomou rapidamente desporto.

Caso D, mulher de 25 anos.

Dor difusa no punho sem traumatismo recente, considerado acidente laboral.

TAC - quisto sinovial intraósseo do semi-lunar e pseudartrose da apófise do unciforme.

Operada - excisão da apófise e enxerto ósseo do quisto.

Persistência das dores.

Caso E, homem de 35 anos, trabalhador da construção civil.

Traumatismo directo da mão direita 2 meses antes com dores persistentes na eminência hipoténar. TAC revelou fractura da apófise unciforme. Excisão cirúrgica. Alta sem dores pouco tempo depois. 